\title{
Comparison of efficacy safety morbidity and complications of conservative and surgical management of ectopic pregnancies in government TD medical college, Alappuzha, Kerala, India
}

\author{
Laila C. Markose, Sathiamma P. K.*
}

Department of Obstetrics and Gynecology, Government TD Medial College Alappuzha, Kerala, India

Received: 29 January 2017

Accepted: 02 March 2017

\author{
*Correspondence: \\ Dr. Sathiamma P. K., \\ E-mail: sathiammapk@ymail.com
}

Copyright: (c) the author(s), publisher and licensee Medip Academy. This is an open-access article distributed under the terms of the Creative Commons Attribution Non-Commercial License, which permits unrestricted non-commercial use, distribution, and reproduction in any medium, provided the original work is properly cited.

\begin{abstract}
Background: Ectopic pregnancy is pregnancy with implantation of fertilized ovum outside the uterine cavity most commonly in the fallopian tube. Objective of the study was to compare the efficacy, safety, morbidity and complications of conservative and surgical management of ectopic pregnancy.

Methods: This is a descriptive study at Government Medical College Alappuzha, Kerala, India to analyze safety morbidity efficacy and complications of conservative medical and surgical management of cases of ectopic pregnancy admitted over a period of one year from May 2011 to April 2012. The study group comprised of 81patients with early pregnancy complaining of abdominal pain, vaginal bleeding, amenorrhoea and no intra uterine gestationsonologically. After confirming diagnosis management options included conservative, surgical or medical management with methotrexate as per selection criteria. Maternal morbidity in terms of hospital stay, blood transfusion, side effects of drugs were compared in both groups.

Results: Accurate diagnoses of cases were done. Presenting complaints of the study subjects where vaginal bleeding, abdominal pain and amenorrhoea, which was in variably present in all subjects. Laparotomy done in $71.6 \%$ case, methotrexate given for $27.2 \%$ cases, laparoscopy for $1.2 \%$ all without significant morbidity. Two cases of failed medical management had laparotomy in view of tubal rupture.Blood transfusion given for $18.4 \%$ case.

Conclusions: Hospital stay was more in medically managed group. Sticking on to proper selection criteria both methods are safe and effective without any complications or failure.
\end{abstract}

Keywords: Betah CG, Ectopic pregnancy, Medical management, Methotrexate, Surgical management, Transvaginal ultrasound

\section{INTRODUCTION}

Ectopic pregnancy is pregnancy with implantation of fertilized ovum outside the uterine cavity most commonly in the fallopian tube. Incidence of ectopic pregnancy has been increasing steadily during past three decades. It continues to be a leading cause of death in first trimester. Ninety percent as result of intraperitoneal hemorrhage.

Ectopic pregnancy is most often associated with risk factor leading to tubal damage and altered embryo transport. Increased incidence may be the result of assisted reproductive techniques. Earlier diagnosis is possible with sensitive pregnancy tests and transvaginal ultrasound. Probability of detecting a gestational sac by endovaginal sonography 22-25 days after conception is 95 percent. Clinical manifestations depend on whether ectopic rupture has occurred or not.

Modern diagnostic techniques permit early recognition of most ectopic pregnancies. Attention has shifted from emergency surgery for the control of life threatening 
hemorrhage to medical treatment aimed at avoiding surgery and preserving reproductive tract anatomy and fertility. At times identification of early unruptured tubal pregnancy may be difficult but clinical suspicion, diagnostic methods and careful evaluation helps to reach correct diagnosis

In 1982 Tanaka reported treatment of interstitial ectopic pregnancy with 15 days course of intramuscular methotrexate being the first report of methotrexate use in treatment of ectopic pregnancy, which later on became the most accepted therapy for medical management of ectopic pregnancy and management of ectopic pregnancy has changed from a totally surgical condition to a medically amenable condition in carefully selected cases.

Objective of the study was to compare the efficacy, safety, morbidity and complications of conservative medical and surgical management of ectopic pregnancies and to find out common predisposing factors in the etiology of ectopic pregnancy.

\section{METHODS}

A comparative study of analysis of conservative, medical and surgical management of cases of ectopic pregnancy admitted over a period of one year from May 2011 to April 2012 at TDMC Alappuzha, Kerala. Factors taken into consideration were age, parity, obstetric history, clinical presentation, USS, gestational sac size, serum beta hCG level, modes of management and its outcome. Expectant management was considered in the patients who had tubal ectopic pregnancy only, low beta hCG, diameter of ectopic mass $<3.5 \mathrm{~cm}$, no evidence of intraabdominal bleeding or rupture by transvaginal scan. Medical treatment was considered for clinically stable patients with unruptured ectopic, non-viable pregnancy, beta hCG $<10,000 \mathrm{Miu} / \mathrm{ml}$, gestational sac size $<3 \mathrm{~cm}$,hemoperitoneum less than $40 \mathrm{ml}$. Methotrexate was given as IV infusion of 50mg per meter square as single dose and patients were followed up by serum beta hCG on day 4 and day 7 .

Surgery was considered when there is tubal rupture or tubal abortion, tubal pregnancy more than $3 \mathrm{~cm}$,presence of cardiac activity, non-compliant patient or failed medical treatment at laparotomy either slapingostomy or segmental resection or slapingectomy was done depending upon the intraoperative picture, contralateral tubal status and desire for fertility. Maternal morbidity in terms of hospital stay, blood transfusion, side effects of drugs was compared in both groups. Currently the most commonly used methotrexate regime is the single dose protocol (Table 1). However it includes a provision for an additional dose of methotrexate when the response to the first dose is inadequate as per serum beta hCG level and ultrasonography.

Once hCG levels have met the criteria for initial decline, hCG level should be followed serially at weekly intervals to ensure that concentrations decline steadily and comes to $<15 \mathrm{mlU} / \mathrm{ml}$. Serial ultrasonographic examinations after methotrexate treatment are not necessary because ultrasonographic findings cannot demonstrate or predict treatment failure unless evidence of recent tubal rupture is observed. Complete resolution of pregnancy usually takes between 2 and 3 weeks from initial treatment and 6 to 8 weeks when pretreatment hCG levels are in higher ranges. Rise or plateau of beta HCG after declinemay indicates persistent ectopic and surgical intervention is usually done. Data is collected when patients reports to the department and follow up was done till discharge from hospital. Mode of management and outcome recorded and collected data is then analyzed statically using Epi Info 2000 Statistical package.

\section{RESULTS}

In this study $32.1 \%$ wasfrom low income group, $67.9 \%$ from middle income group. Presenting complaint of the study subjects were vaginal bleeding abdominal pain and amenorrhoea. Amenorrhoea was invariably present in all subjects. Vaginal bleeding was present in $30(37 \%)$ cases and no vaginal bleeding in $51(63 \%)$ cases. Among the 81 subjects $68(84 \%)$ of them presented with amenorrhoea and abdominal pain while $13(16 \%)$ were not having abdominal pain. Majority of them were G2P1. Next comes primi, then G3P2L2 and G6 there were 2 patients (Table 2).

Table 1: Single dose mtx treatment protocol.

\begin{tabular}{|ll|l|}
\hline Treatment day & $\begin{array}{l}\text { Laboratory } \\
\text { evaluation }\end{array}$ & Intervention \\
\hline $\begin{array}{l}\text { Pretreatment } \\
\text { day. }\end{array}$ & $\begin{array}{l}\text { hCG, CBC with } \\
\text { differential, liver } \\
\text { function tests, } \\
\text { creatinine, blood type } \\
\text { \& Rh and beta hCG. }\end{array}$ & $\begin{array}{l}\text { Anti D given if } \\
\text { Rh negative. }\end{array}$ \\
\hline Day 1 & Beta hCG & $\begin{array}{l}\text { MTX 50mg/m2 } \\
\text { IV }\end{array}$ \\
\hline Day 4 & Beta hCG & $\begin{array}{l}\text { None (hCG may } \\
\text { rise) }\end{array}$ \\
\hline Day 7 & Beta hCG & $\begin{array}{l}\text { Repeat MTX } \\
50 \mathrm{mg} / \mathrm{m} 2 \text { IV if } \\
\text { hCG decreased } \\
\text { to <15\% } \\
\text { between Day 4 } \\
\text { and Day 7 }\end{array}$ \\
\hline & & \\
& & \\
& & \\
& &
\end{tabular}

Table 2: Obstetric score.

\begin{tabular}{|ll|l|}
\hline Gravida & Number & Percentage \\
\hline PRIMI & 21 & 26 \\
\hline G2 & 30 & 37 \\
\hline G3 & 16 & 28 \\
\hline G4 & 5 & 6 \\
\hline G6 & 2 & 2 \\
\hline
\end{tabular}


Table 3: History of abdominal surgery.

\begin{tabular}{|lllll|}
\hline Surgery & Frequency & Percent & Valid percent & Cumulative percent \\
\hline 2 LSCS & 1 & 1.2 & 1.2 & 1.2 \\
\hline Laparotomy for ectopic & 3 & 3.7 & 3.7 & 4.9 \\
\hline 1 LSCS & 20 & 24.7 & 24.7 & 29.6 \\
\hline NIL & 57 & 70.4 & 70.4 & 100.0 \\
\hline Total & 81 & 100.0 & 100.0 & 3 \\
\hline
\end{tabular}

Table 4: Treatment given.

\begin{tabular}{|lllll|}
\hline Treatment & Frequency & Percent & Valid percent & Cumulative Percent \\
\hline Laparoscopy & 1 & 1.2 & 1.2 & 1.2 \\
\hline Laparotomy & 58 & 71.6 & 71.6 & 72.8 \\
\hline Mtx & 22 & 27.2 & 27.2 & 100.0 \\
\hline Total & 81 & 100.0 & 100.0 & \\
\hline
\end{tabular}

Table 5: Surgical treatment-hospital stay.

\begin{tabular}{|lllll|}
\hline Number of days & Frequency & Percent & Valid percent & Cumulative percent \\
\hline 4 & 12 & 20.7 & 20.7 & 20.7 \\
\hline 5 & 18 & 31.0 & 31.0 & 51.7 \\
\hline 6 & 19 & 32.8 & 32.8 & 84.5 \\
\hline 7 & 4 & 6.9 & 6.9 & 91.4 \\
\hline 8 & 1 & 1.7 & 1.7 & 93.1 \\
\hline 9 & 1 & 1.7 & 1.7 & 94.8 \\
\hline 10 & 1 & 1.7 & 1.7 & 96.6 \\
\hline 17 & 1 & 1.7 & 1.7 & 98.3 \\
\hline 18 & 1 & 1.7 & 1.7 & 98.3 \\
\hline Total & 58 & 100 & 100 & 100 \\
\hline
\end{tabular}

History of abortion was present in 11 subjects (13.5\%) subjects. Thyroid dysfunction was present in $4(4.9 \%)$ patients. History of ovulation induction was there in14 $(17.3 \%)$ cases. Previous surgical history include one caesarean in $20(24.7 \%)$ patients, two caesarean in $1(1.2 \%)$ laparotomy for ectopic pregnancy $3(3.7 \%)$ cases (Table 3). History of tubal sterilization was present in (14 $(17.3 \%)$ cases and $67(82.7 \%)$ were not sterilized.
Table 6: Medical treatment hospital stay.

\begin{tabular}{|ll|}
\hline Mean & 22.68 \\
\hline Median & 21.00 \\
\hline Mode & 13 \\
\hline Std Deviation & 11.54 \\
\hline Minimum & 5 \\
\hline Maximum & 55 \\
\hline
\end{tabular}

Table 7: Failed medical treatment.

\begin{tabular}{|c|c|c|c|c|c|}
\hline & & Frequency & Percent & Valid percent & Cumulative percent \\
\hline \multirow[t]{4}{*}{ Valid } & 0 & 20 & 24.7 & 24.7 & 24.7 \\
\hline & 1 & 2 & 2.5 & 2.5 & 27.2 \\
\hline & & & & & 100.0 \\
\hline & Total & 81 & 100.0 & 100.0 & \\
\hline
\end{tabular}

Out of the 81 studied cases 70 (86.4\%) were hemodynamically stable and $11(13.6 \%)$ patients were in aclinically unstable condition. Laparotomy done for 58 (71.6\%) cases. Methotrexate given for 22 (27.2\%) cases.
Laparoscopy for $1(1.2 \%)$ (Table 4). Out of 58 cases who had surgery $15(18.4 \%)$ patient required blood transfusion, seven case $(8.6 \%)$ required 1 unit blood transfusion and $8(9.8 \%)$ had 2 units blood transfusion. 
Two cases failed to respond medical treatment underwent laparotomy. One patient had Laparoscopic bilateral salpingectomy for resterilization. Those who underwent laparotomy duration of hospital stay varied from4-18 days (Table 5). In the medically managed group duration of hospital stay varied from8 to 55 days (Table 6). People from remote areas are forced to have prolonged stay till regression.

After medical treatment beta hCG found to drop drastically from day 4 to day 7 . Two of the medically treated cases failed to respond and underwent laparotomy (Table 7).

\section{DISCUSSION}

This is a descriptive study conducted for 1 year period from May 2011to April 2012. Study is carried out in 81 patients who were diagnosed to have ectopic pregnancy. No significant impact of age was found contributing to etiology of ectopic pregnancy. Clinical, laboratory and ultrasonography findings determined the diagnosis. Patients who are hemodynamically stable, with serum betahCG less than $10,000 \mathrm{mlU} / \mathrm{ML}$, gestational sac less than or equal to $3.5 \mathrm{~cm}$ with or without cardiac activity and those patients compliant for regular follow up were given methotrexate.

In this sample, majority of patients were from the middle income group showing that economic status was not a factor to reduce the incidence of ectopic. Out of 81 cases $21(26 \%)$ patients were primigravidae, main reason being ovulation induction for infertility. As per Morris JM and Van Wagenen $G$ ovulation induction has been an important etological factor for ectopic pregnancy. Clomiphene citrate was the main ovulation induction agent that caused the insult. Similar inference was made by Marchbanks PA et al. ${ }^{1,2}$ In higher gravid neither the history of previous abortion nor ectopic had any influence in succeeding ectopic gestation. According to Burkman $\mathrm{RT}$, et al increased risk of ectopic following induced abortion has been seen. Apart from primigravid patients, majority of study population who were second gravidae with $1^{\text {st }}$ FTND fell in the low risk group..$^{3-5}$

Co morbidity like PID or pelvic adhesion were not seen. The major comorbidity was hypothyroidism and risk of ectopic pregnancy may be due to suboptimal embryo quality. $86.4 \%$ patients presented early were treated medically or surgically with minimal morbidity. Only $13.6 \%$ patients presented in shock or unstable condition but had no morbidity following treatment. Previous history of ectopic was not significant etiological factor in the study group. Major surgical cause which contributed to ectopic pregnancy was caesarean section, the reason may that majority of patients were belonging to younger age group and increase in caesarean section rate has contributed to increase incidence of tubal gestation.
From time immemorial Tubal surgery has been implicated to cause ectopic pregnancies. Cheng MC, et al also has reported similar incidence of tubal gestation following sterilization. ${ }^{4,5}$ In the study group also, sterilized patients contributed to $17 \%$. However this was less than primigravida patients, then reason could be attributed to smaller sample size of the study.

One case was diagnosed after culdotomy. Rest were diagnosed with USS which highlights importance of noninvasive investigation in diagnosis Tritsch IE, et al confirms to this. ${ }^{6}$ Diagnosis is confirmed by USS in $96.6 \%$ however $4.4 \%$ with inconclusive USS findings diagnosis made by serial Beta hCGC Stenman UH, et al. In suspected ectopic pregnancy, ultrasound findings and hCG levels assessed by an immunoflurometric assay. ${ }^{7}$ Beta hCG follow up done for methotrexate group which was very sensitive in showing disease regression. Out ofthe 81 patients, main stay of treatment was medical and surgical with strict adherence to inclusion criteria. Singledose merhotrexate, an expanded clinical trial. ${ }^{8}$

Out of 22 medically treated, only 2 needed laparotomy. As the people were from remote area they needed a prolonged hospital stay during medical treatment. Surgical treatment was given for 58 patients, except 1 patient all of them had laparotomy due to non-availability of endoscopy. A comparison of laparoscopy and laparotomy for the treatment of ectopic pregnancy. ${ }^{9}$

But when compared to medical treatment advantage of this group is that they had a shorter hospital stay. The main morbidity was patient requiring blood transfusion. Of them, only 15 patients needed blood transfusion apart from which no significant morbidity was reported.

\section{CONCLUSION}

Ectopic gestation is still remaining a major problem in the reproductive age group commonest site being the fallopian tube. With increase in incidence of infertility ovulation induction remains an important cause of ectopic pregnancy in primi gravid patients.

Increased incidence of caesarean section contributes to increase in ectopic gestation as seen in the present study. Ultrasound remains the main imaging modality that helps in early detection of disease in the study group. Serial Beta hCG measurement was the main stay in deciding the success of medical treatment.

However for patients from remote area, medical treatment requires prolonged hospital stay compared with medical treatment. Single dose Methotrexate again proved to be a very powerful and successful drug in the treatment of tubal gestation without any significant morbidity or complications. Laparotomy still remains the main modality of treatment for ectopic gestation in places with poor resource setting. 


\section{ACKNOWLEDGEMENT}

Author would like to acknowledge the faculties and other staff of the department of Obstetrics and Gynecology, Government TD Medical College, Alappuzha, Kerala, India, for their respective assistance in preparing this manuscript.

Funding: No funding sources

Conflict of interest: None declared

Ethical approval: The study was approved by the Institutional Ethics Committee

\section{REFERENCES}

1. Morris JM, Wagenen G. Interception- the use of post ovulatory estrogens to prevent implantation. Am J Obstet Gynecol. 1973;115:101.

2. Marchbanks PA, Coulam CB, Annegers JF. An association between clomiphene citrate and ectopic pregnancy:a preliminary report. Fertil Steril. 1985;44:268-70.

3. Burkman RT, Mason KJ, Gold EB. Ectopic pregnancy and prior induced abortion. Contraception. 1988;37:21-7.

4. Cheng MC, Wong YM, Rochat RW. Sterilization failures in Singapore: an examination of ligation techniques and failure rates. Stud Fam Plann. 1977:8:109-15.

5. Stefano F, Peterson HB, Layde PM. Risk of ectopic pregnancy following tubal sterilization. Obst Gynecol. 1982:60:326-30.

6. Tritsch IE, Yeh MX, Peisner DB. The use of trans vaginalsonography in the diagnosis of ectopic pregnancy. Am J Obstet Gynecol. 1989;161:157-61.

7. Cacciatore B, Ylostalo P, Stenman UH, et al. Suspected ectopic pregnancy: ultrasound findings and hCG levels assessed by an immunoflurometric assay. Br J Obstet Gynaecol. 1988:95:497-502.

8. Jain KA, Hamper UM, Sanders RC. Comparison of transvaginal and transabdominal sonography in the detection of early pregnancy and its complications. Am J Roentjenol. 1988:151:1139-1.

9. Stoval TG, Ling FW. Single-dose merhotrexate : an expanded clinical trial. Am J Obstet Gynacol. 1993:170:1840-1.

10. Brumsted J, Kessler C, Gibson C. A comparison of laparoscopy and laparotomy for the treatment of ectopic pregnancy. Obstet Gynecol. 1988:71:889-92.

Cite this article as: Markose LC, Sathiamma PK. Comparison of efficacy safety morbidity and complications of conservative and surgical management of ectopic pregnancies in government TD medical college, Alappuzha, Kerala, India.Int J Reprod Contracept Obstet Gynecol 2017;6:1473-7. 